\title{
Modelling discontinuous well log signal to identify lithological boundaries via wavelet analysis: An example from KTB borehole data
}

\author{
Amrita Singh ${ }^{1}$, Saumen Maiti $^{1, *}$ and R K Tiwari ${ }^{2}$ \\ ${ }^{1}$ Indian School of Mines (ISM), Dhanbad 826 004, India. \\ ${ }^{2}$ CSIR - National Geophysical Research Institute, Hyderbad 500 00\%, India. \\ ${ }^{*}$ Corresponding author. e-mail: saumen_maiti2002@yahoo.co.in
}

Identification of sharp and discontinuous lithological boundaries from well log signal stemming from heterogeneous subsurface structures assumes a special significance in geo-exploration studies. Well log data acquired from various geological settings generally display nonstationary/nonlinear characteristics with varying wavelengths and frequencies. Modelling of such complex well-log signals using the conventional signal processing techniques either fails to catch-up abrupt boundaries or at the best, do not provide precise information on insidious lithological discontinuities. In this paper, we have proposed a new wavelet transform-based algorithm to model the abrupt discontinuous changes from well log data by taking care of nonstationary characteristics of the signal. Prior to applying the algorithm on the geophysical well data, we analyzed the distribution of wavelet coefficients using synthetic signal generated by the first order nonstationary auto-regressive model and then applied the method on actual well log dataset obtained from the KTB bore hole, Germany. Besides identifying the formation of layered boundaries, the underlying method also maps some additional formation boundaries, which were hitherto undetected at the KTB site. The results match well with known geological lithostratigraphy and will be useful for constraining the future model of KTB bore hole data.

\section{Introduction}

Modelling formation boundaries from discontinuous well $\log$ records is one of the fundamental tasks for geologists and petro-physicists. However, setting the feasible criteria to recognize the formation boundary is subjective to the individual experience. Log analyst may put different criteria to identify the same formation boundary or they may set same criteria to choose different formation boundaries. Therefore, the consistency of final results is subject to the individual choice of suitable criteria and their experience that may lead to ambiguous result (Dewan 1983; Lanning and Johnson 1983; Hsieh et al. 2005; Maiti and Tiwari 2005). The well log data is often tamed by the different types of noises that may further result in complex nonlinear and nonstationary characteristics. Traditional signal processing technique (e.g., Fourier analysis, Walsh analysis) can be useful to extract the meaningful information from geophysical well log signal. Particularly, Walsh transformbased boundary detection has been used to extract the blocky/stepping nature of the lithologic succession (Lanning and Johnson 1983; Maiti and Tiwari 2005). However, these techniques are linear

Keywords. Fast Fourier transform (FFT); continuous wavelet transform (cwt); discrete wavelet transforms (dwt); lithological boundary identification; KTB. 
and not appropriate for the nonstationary well log signals. Further, in Walsh domain, the step width remains constant throughout the entire length of the well-log records and is decided by the cut-off sequency (Lanning and Johnson 1983; Maiti and Tiwari 2005). Therefore, choosing cut-off sequency is crucial to resolve minimum thickness present in the geologic layers. The main limitations of this approach are as follows:

- detection of thinner layer less than that of stepwidth decided by the cut-off sequency is not possible

- takes longer time to detect relatively thin layer boundaries

- detection of precise position of the bed boundary is not trivial.

The correct position of the bed boundary may change if the real location of a boundary is not a multiple of step-width decided by the cut-off sequency from the beginning of the data up to the end of the log. The energy distribution is shifted at the boundary by half of the step-width using Walsh low pass sequenecy filtering method.

Recently, several researchers have suggested that wavelet based algorithm could be an appropriate choice to handle the nonstationary part of the geophysical signal (Morlet et al. 1982; Mallat 1989; Wickerhauser 1994; Kumar and FoufoulaGeorgiou 1997; Oppenheim et al. 1999; Boggess and Narcowich 2001; Frantziskonis and Denis 2003; Soliman et al. 2003; Misti et al. 2007; Chamoli et al. 2007; Pan et al. 2008; Chamoli et al. 2010; Adamowski and Chan 2011; Chandrashekhar and Rao 2012; Perez-Munoz et al. 2013). Researchers have invariably used wavelet transform to solve geophysical characterization problem. The underlying method provides a flexible depth-scale window that narrows down the small scale features and widens on large-scale features, analogous to a zoom lens (Kumar and Foufoula-Georgiou 1997; Javid and Tokhmechi 2012). Recently, the wavelet transform combined with Fourier transform was applied to identify the stratigraphic formation interfaces from gamma ray (GR) log and spontaneous potential (SP) log (Pan et al. 2008). The underlying method is robust for specific log data and has been applied to detect the main lithologic boundary by choosing the correct frequency band. However, method is not fully automated, which is essential to handle voluminous amount of well log data acquired by industry. It is, therefore, imperative to develop an alternative new algorithm, which could be used to overcome the existing problems.

Multiple mathematical techniques/algorithms have been developed and successfully applied to solve numerous geophysical problems (Hsieh et al. 2005; Leonardi and Kumpel 1999; Maiti et al.
2007; Maiti and Tiwari 2010). For example, several techniques of spectral analyses (Fourier, Walsh, wavelet transforms) and fractal theory have been applied to solve the various geophysical problems. For instance, (i) log analysis (Doveton 1986; Pan et al. 2008), (ii) reservoir characterization (Alvarez et al. 2003), (iii) climate signal detection (Lau and Weng 1995), (iv) chemical analysis (Leung et al. 1998), and (v) conjunction model for groundwater level forecasting (Adamowski and Chan 2011). KTB research geoscientist team has examined the fractal behaviour of well-log signal variability, presuming that well-log signals in the super deep German Continental Deep Drilling Program (KTB) borehole display nonlinear characteristics (Leonardi and Kumpel 1999). Based on the above study, the researchers have observed that nonlinear well-log data reveal signatures of crustal heterogeneities.

We therefore, propose a new algorithm based on wavelet transforms to model the discontinuities and identify boundaries from the nonstationary well log data. First we tested the developed method on first order auto-regressive model $(\mathrm{AR}(1))$. Then we applied the method to density (RHOB), neutron porosity (NPHI), gamma (spectral gamma ray (SGR)), seismic $\mathrm{P}$-wave transit travel time (DTCO), and electrical resistivity (LLD) data from KTB pilot and main hole drilled in complex metamorphic region of central Europe where metamorphism leads to facies change. Although, there are several excellent literatures in the domain of spectral techniques, we, however, briefly provide the mathematical background of wavelet transform for self-sufficiency of the paper.

\section{Mathematical background}

\subsection{Wavelet transforms (WT)}

Wavelet transform allows us to perform multi-scale analysis, which is vital for analysing nonstationary records. It provides good localization properties in both depth and frequency domains (Perez-Munoz et al. 2013). Moreover, such transformations are associated with different shapes and sizes of functions (a family of functions) called wavelet. A wavelet function is defined as (Goupillaud et al. 1985; Perez-Munoz et al. 2013)

$$
\psi_{u, s}(z)=\frac{1}{\sqrt{(s)}} \psi\left(\frac{z-u}{s}\right), \quad u>0, s \in R
$$

where the function $\psi$ is called the mother wavelet, $s$ is the scale factor which determines the wavelength and $u$ denotes the shift of the wavelet 
(Goupillaud et al. 1985). In the wavelet transform, the signal analysed is convolved with mother wavelet and the transformation is computed for different segments of the data by varying both $s$ and $u$. The continuous wavelet transform (CWT) of signal $f(z)$ that assumes only the continuous values of scale and shift parameters can be defined as:

$$
C W T_{f}(u, s)=\frac{1}{\sqrt{|s|}} \int_{-\infty}^{\infty} f(z) \psi^{*}\left(\frac{z-u}{s}\right) d z
$$

where $*$ represents the complex conjugate. It is worth making a note of the fact that CWT needs a large amount of computation time and storage in comparison to discrete wavelet transform (DWT) to implement. In the DWT, variations are expressed by dyadic increase of scale and shift parameter (based on power of two). Accordingly, the scale and shift parameters are discretized as $s=s_{0}^{m}$ and $u=n u_{0} s_{0}^{m}$. The resulting wavelets are defined as:

$$
\psi_{m, n}(z)=u_{0}^{-m / 2} \psi\left(\frac{z-n u_{0} s_{0}^{m}}{s_{0}^{m}}\right)
$$

where $m$ and $n$ are integer values. The DWT is defined as:

$$
D W T_{f}(m, n)=\int_{-\infty}^{\infty} f(z) \psi_{m, n}(z) d z .
$$

The matrix of the wavelet coefficients, $C W T_{f}(u, s)$ and $D W T_{f}(m, n)$ is represented by scalogram which indicates the frequency localization to different scales and shifts.

\subsection{Wavelet decomposition}

A fast DWT algorithm developed by Mallat (1989) consists of decomposition of signal into one or more levels of resolution by four filters including decomposition low-pass, decomposition high-pass, reconstruction low-pass and reconstruction high-pass. The low pass filter, associated with scaling function $\phi_{j, k}$ produces gross structure of the signal while high pass filter, associated with wavelet function $\psi_{j, k}$ produces detail structure of the signal. The scaling and wavelet functions are defined as (Mallat 1989):

$$
\begin{aligned}
& \phi_{j, k}(n)=2^{j / 2} \phi\left(2^{j} n-k\right) \\
& \psi_{j, k}(n)=2^{j / 2} \psi\left(2^{j} n-k\right)
\end{aligned}
$$

where $j$ represents scale level and $k$ represents translation in that scale level. The scaling function provides the flexibility to approximate a given signal with desired level of accuracy. For discrete signal $f(n)$ defined in $[0, N-1]$ with $N$ data points, wavelet coefficients are estimated by the following equations (Perez-Munoz et al. 2013)

$$
\begin{aligned}
& W_{\phi}(j, k)=\frac{1}{\sqrt{N}} \sum_{n} f(n) \phi_{j, k}(n) \\
& W_{\psi}(j, k)=\frac{1}{\sqrt{N}} \sum_{n} f(n) \psi_{j, k}(n)
\end{aligned}
$$

where $W_{\phi}(j, k)$ and $W_{\psi}(j, k)$ are the approximation coefficients and detail coefficients.

The original signal $f(z)$ is reconstructed by using the inverse wavelet transform of the approximation and detail coefficients as follows (Misti et al. 2007).

$$
f(z)=W_{\phi l}+\sum_{i \leq l} W_{\psi i} .
$$

The original signal can be obtained from the sum of these two coefficients. By using DWT, we obtain detail coefficient which is used to reconstruct the high-frequency signal. In the present work, the detail response was considered for modelling finer structure of KTB crust.

\section{Study on KTB borehole data}

The German Continental Drilling Program (KTB) is situated in the northeastern Bavaria, southern Germany (figure 1). The continental crust is composed of three main lithologic/lithofacies units: paragneisses, metabasites and alternations of gneiss-amphibolites, with minor occurrence of marbles, calc-silicates, orthogeneisses, lamprophyres and diorites (Emmermann and Lauterjung 1997; Pechnig et al. 1997; Leonardi and Kumpel 1999). The depth of the pilot hole is $4000 \mathrm{~m}$ and the total depth of main hole is $9101 \mathrm{~m}$. The borehole data are sampled at $0.1524 \mathrm{~m}$ intervals (6 inches). We have used here five sets of well log data (viz., gamma ray, neutron porosity, density, resistivity, and sonic) to detect the boundary via waveletbased automated system. It can be noted that in the metamorphic crystallised basement environment at KTB drill site, gamma ray is found to be the most important log that captures the changes of lithologic succession. In the KTB geological study, gamma ray activity exhibits a general increase from the most mafic formation (ultramafites) to the most acidic formation (potassiumfeldspar gneisses) due to combination of $\mathrm{K}$, Th and U. The massive metabasite units are physically characterized by lower gamma ray activity and higher density than the formations of the paragneisses sections (Pechnig et al. 1997; Maiti and 


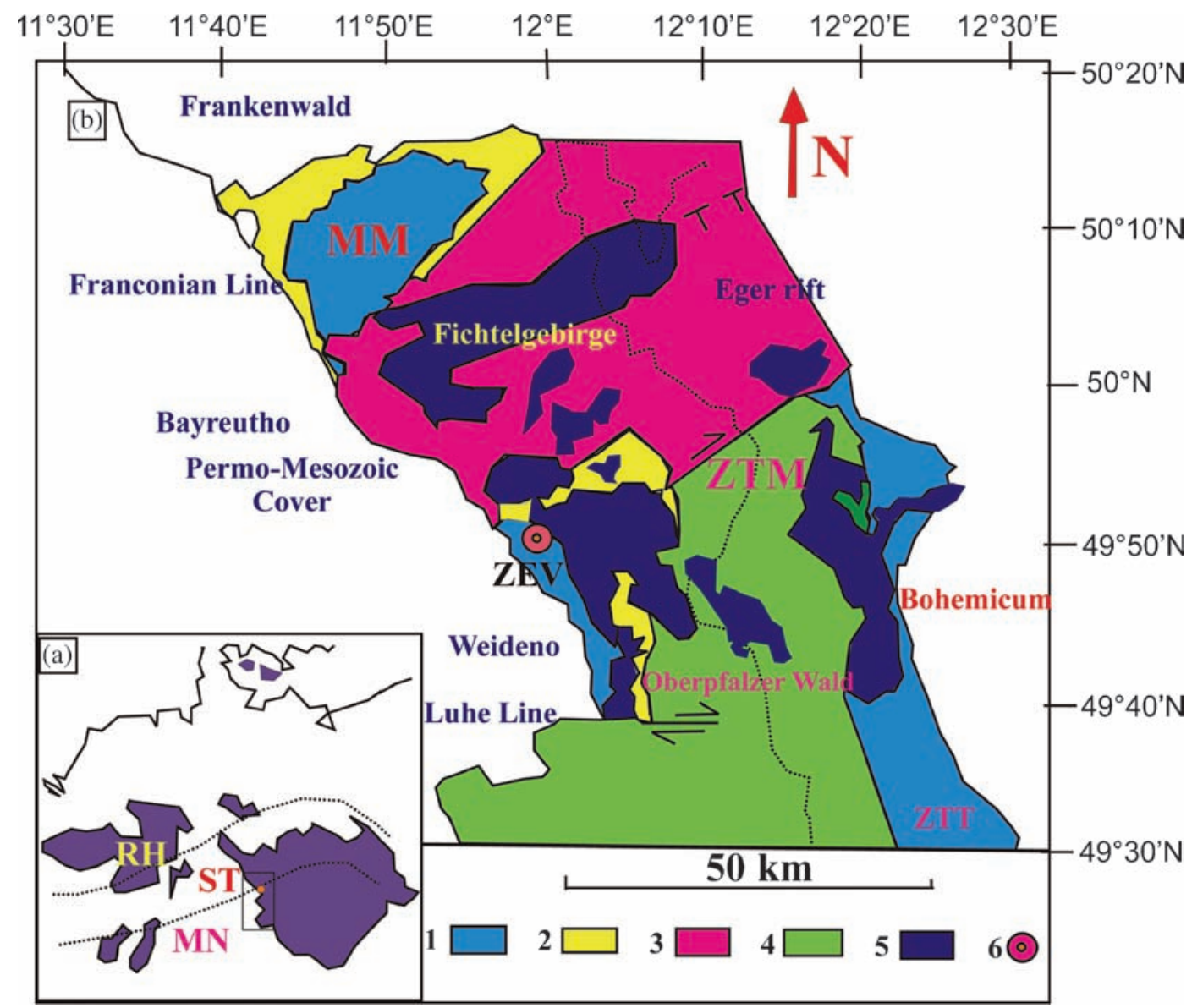

Figure 1. Geological map of the KTB drill site and vicinity (after Pechnig et al. 1997). (a) Surface exposure of the Variscan orogenic belt in middle Europe. Distinguished are the three tectono-stratigraphic main units of the Rhenoherzynikum $(\mathrm{RH})$, the Saxothuringikum (ST) and the Moldanubikum (MN). (b) (1) Medium-pressured metamorphic units, comprising the Munchberger Gneismasse (MM), the Zone von Tepla-Taus (ZTT), and the Zone von Erbendorf Vohenstrauss (ZEV); (2) greenshist facies units; (3) Saxothuringikum separated by the mylonitic shear zone von Tirschenreuth Mahring (ZTM);

(4) Moldanubikum; (5) post-Variscian granites; and (6) location of the KTB drill site.

Tiwari 2010). This is related to the mineral content, which within metabasites consists of more mafic and dense minerals like hornblende and garnet biotite (Pechnig et al. 1997). The variation of neutron porosity response in crystalline basement formation is mainly due to the changes of mineralogical composition because the pore space in the crystalline basement formation is very low. Enhanced porosity indicates in general the presence of discrete zones of faulting and fracturing. Moreover, neutron porosity in undisturbed zone is predominantly characterized by the waterbound minerals like phyllosilicates or amphiboles (Pechnig et al. 1997). In general, sonic travel time decreases with increasing density and consequently with the amount of mafic minerals. The average travel time in metabasites unit is $160 \mu \mathrm{s} / \mathrm{m}$ whereas in paragneisses unit the travel time varies form 165 to $200 \mu \mathrm{s} / \mathrm{m}$. For electrical logs, resistivity values are generally very high in crystalline basement formations $\left(10^{3}\right.$ and $10^{6} \mathrm{ohm}-\mathrm{m}$ (LLD)).

\section{Mother wavelet and procedure for boundary detection}

\subsection{Mother wavelet}

There are many different types of wavelets which include Daubechies, Symmlet, Coiflet, Meyer, Gaussian, Mexican hat, Morlet, and Shanon wavelets (Seo et al. 2015). Mainly two popular wavelets, e.g., Mexican hat and Morlet (Daubechies 1992) have been used for CWT analysis. For DWT analysis, orthogonal wavelets have been commonly used (e.g., Deubechies). The Haar wavelet is the one which is simplest among all the orthogonal wavelets and resembles a step function (Kumar and Foufoula-Georgiou 1997; Misti et al. 2007; Goumas et al. 2002). It is worth making a note of the fact that geological records are discontinuous in nature at the boundary because of the stepping/abrupt succession of geological formations. The wavelet transform with Haar mother wavelet is being commonly used to emulate the inherent 
blocky/stepping nature of discontinuous well log signals (Misti et al. 2007; Pan et al. 2008; PerezMunoz et al. 2013). It is therefore logical and appropriate to use matching Haar mother wavelet to model discontinuous well log signals in this study.

Figure 2 illustrates the complete procedure for boundary detection. Decomposition of data can be done using discrete mother Haar wavelet in order to obtain the approximation and detail coefficient. The required level of decomposition depends on the scale at which layers are present in the well log. Thus, one need to continue the decomposition until the desired frequency is resolved in the original well log. The detail coefficients represent the high frequency component of the data. From the detail frequency component we can observe the spike against a depth where rapid lithology changes occur. Now we apply inverse wavelet transform to reconstruct the data from detail coefficients and then perform Fast Fourier transform (FFT) for power spectrum analysis of the reconstructed signal (figure 2). In many geological/geophysical situations, we invariably observe some kind of noise, which dominates the field observations and corrupts the actual signal. Moreover, there is the presence of washout, caving, and abnormal mud cake, and other borehole problems, all of which are capable of adversely affecting well $\log$ responses. The inherent noise that often occurs through errors in well log data is usually caused by complex geological situation in the borehole. Assuming that data is assorted with some amount of noise, we employ digital filtering technique on the reconstructed data $\left(R_{D}\right)$ in frequency domain by choosing a proper frequency band from power spectrum of the reconstructed signal and modified reconstructed data (figure 3). After filtering, we use inverse FFT to obtain modified reconstructed data $\left(M_{R D}^{f}\right)$ in depth domain. So, the data are filtered twice using the combined WT and FT method. The logarithmic distribution of filtered data from log transform is calculated using equation (10) (Jang and Jang 2003).

$$
L_{g} R_{D}=69+\log _{2}\left(\frac{M_{R D}^{f}}{440}\right) .
$$

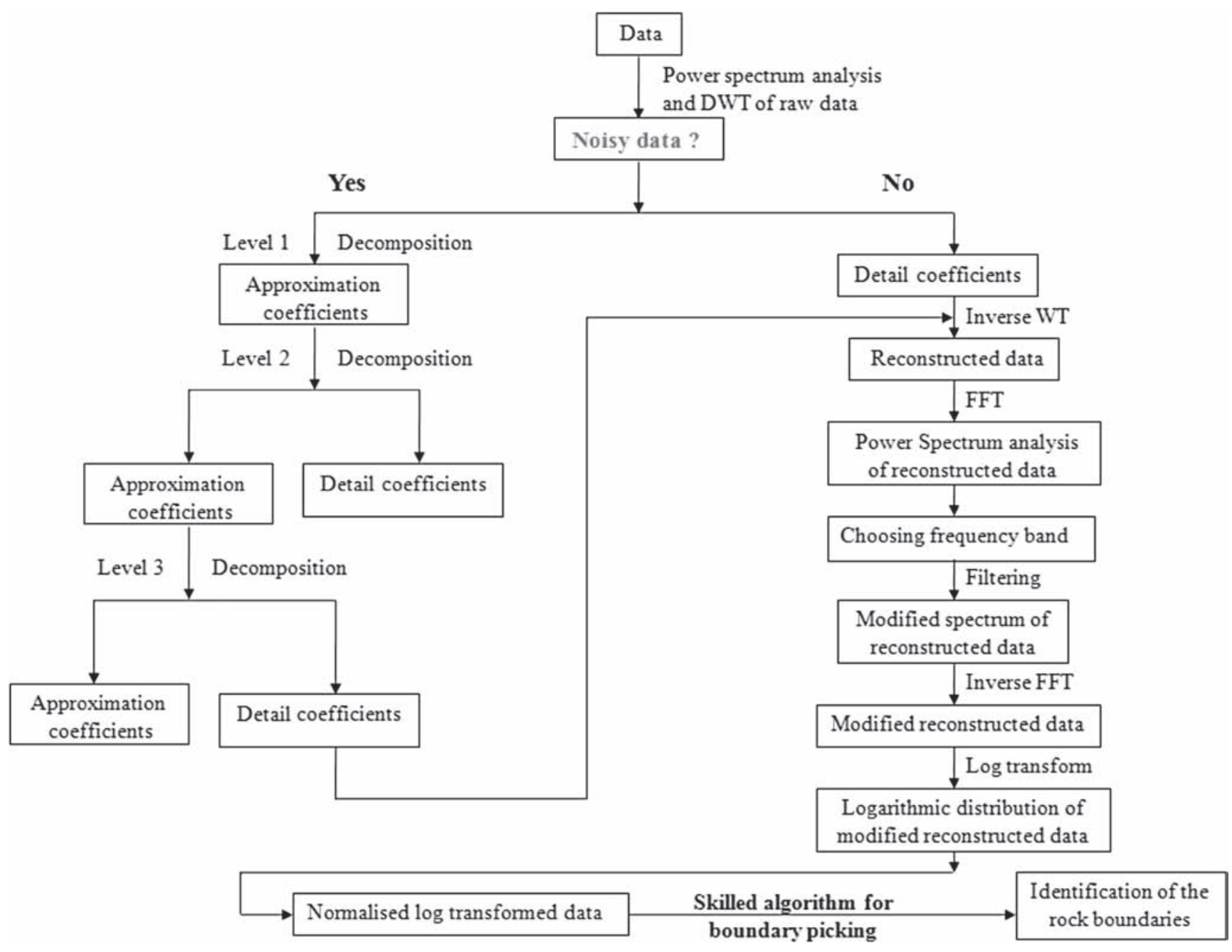

Figure 2. Flowchart of the proposed methodology for boundary detection. 
(a)

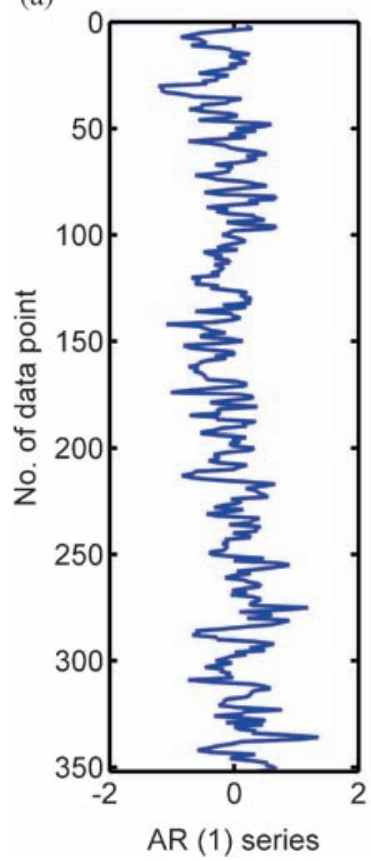

(b)

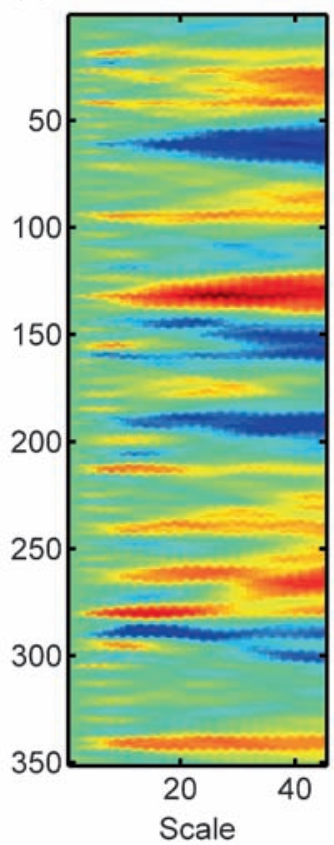

(c)

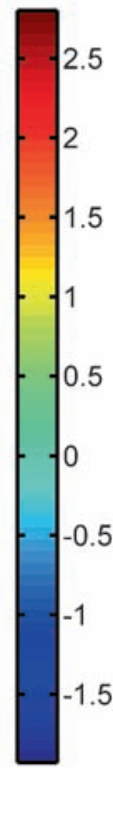

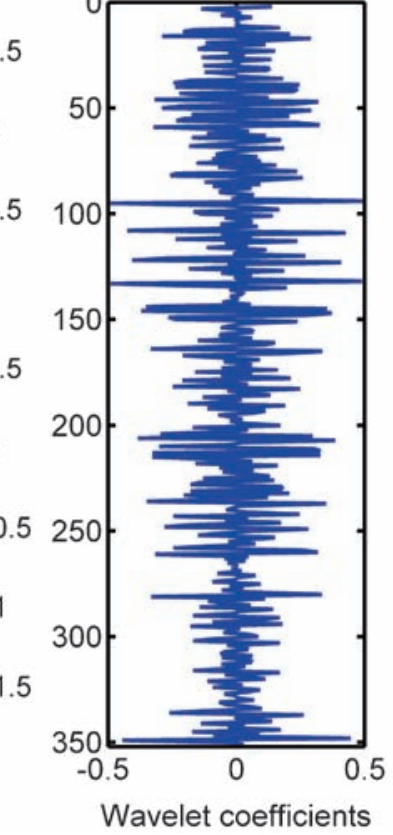

(d)

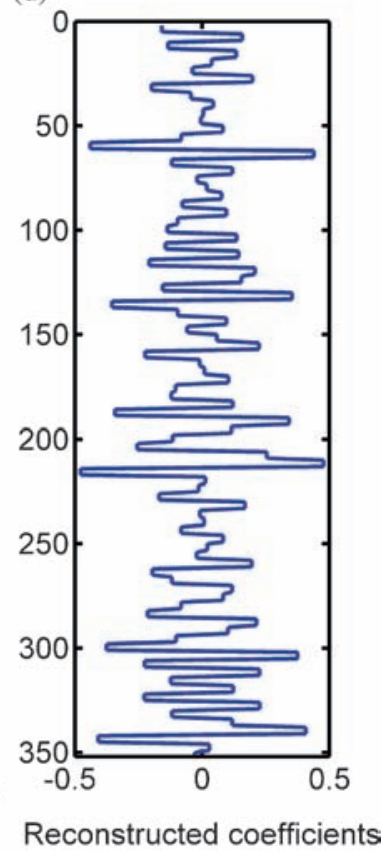

Figure 3. (a) Synthetic data of $\operatorname{AR}(1)$ series and (b) its wavelet scalogram. (c) Detail wavelet coefficients of the signal using discrete wavelet transform. (d) Reconstruction of the signal from detail coefficient.

The constants in equation (10) represent the intercepts in the plot between the logarithmic distribution of filtered data $\left(L_{g} R_{D}\right)$ and modified reconstructed data $\left(M_{R D}^{f}\right)$. We employ skilled algorithm on this logarithmic distribution of $\log$ to detect the lithologic boundary. In the next section we briefly describe the skilled algorithm.

\subsection{Skilled algorithm}

We present an algorithm which is based on wavelet transform technique to identify the finer scale boundary embedded within the larger geological units. At first we normalized the logarithmic distribution of filtered data $\left(L_{g} R_{D}\right)$. This is done by dividing the series with maximum absolute value. The median value of the normalized logarithmic transform of the well log data is calculated for each $\log$ and is considered as a reference value of respective log to start the boundary picking algorithm. Lanning and Johnson (1983) used the depth corresponding to the beginning of the data as the first boundary value. We note that the beginning of the depth may not always be the boundary and therefore we call it here as median boundary value. Accordingly the final procedure is to move to the next step on one of the logs and compute the absolute magnitude of the difference between the normalised value and the reference value. In this way differences are calculated for the whole data with varying reference values according to the signal. This difference is computed for the five logs and then each one was multiplied by the weight chosen for that log. Lastly the results were summed to form the pick value which is a dimensionless number and measure the amount of the energy change taking place simultaneously on all five logs. Now consider a threshold value which is also a dimensionless number and compare it with the pick value. If the pick value is greater or equal to the threshold value, then the depth at the beginning of the step is chosen as a boundary; otherwise new boundary has not been formed and the process is repeated. The proposed methodology with the developed algorithm is depicted as a flowchart in figure 2 .

\section{Results}

\subsection{Application to synthetic data}

Synthetic data with 352 points were generated using a first order auto-regressive model $(\operatorname{AR}(1))$ series with additive Gaussian noise. Upon applying CWT on the data, we can see the sharp gradients, which represent sudden changes in signal (figure 3a). One can differentiate the particular location by means of spike irrespective of using DWT technique (figure $3 \mathrm{~b}$ ). The Haar wavelet is used to generate figure 3(b). The scalogram is charted in colour scale that represents the amplitude of wavelet coefficients. Note that scalogram for $\mathrm{AR}(1)$ model does not give the clear indication of the presence of the boundary/changes (figure 3c). This could be due to the noise present at the same scale as that information needed. In 

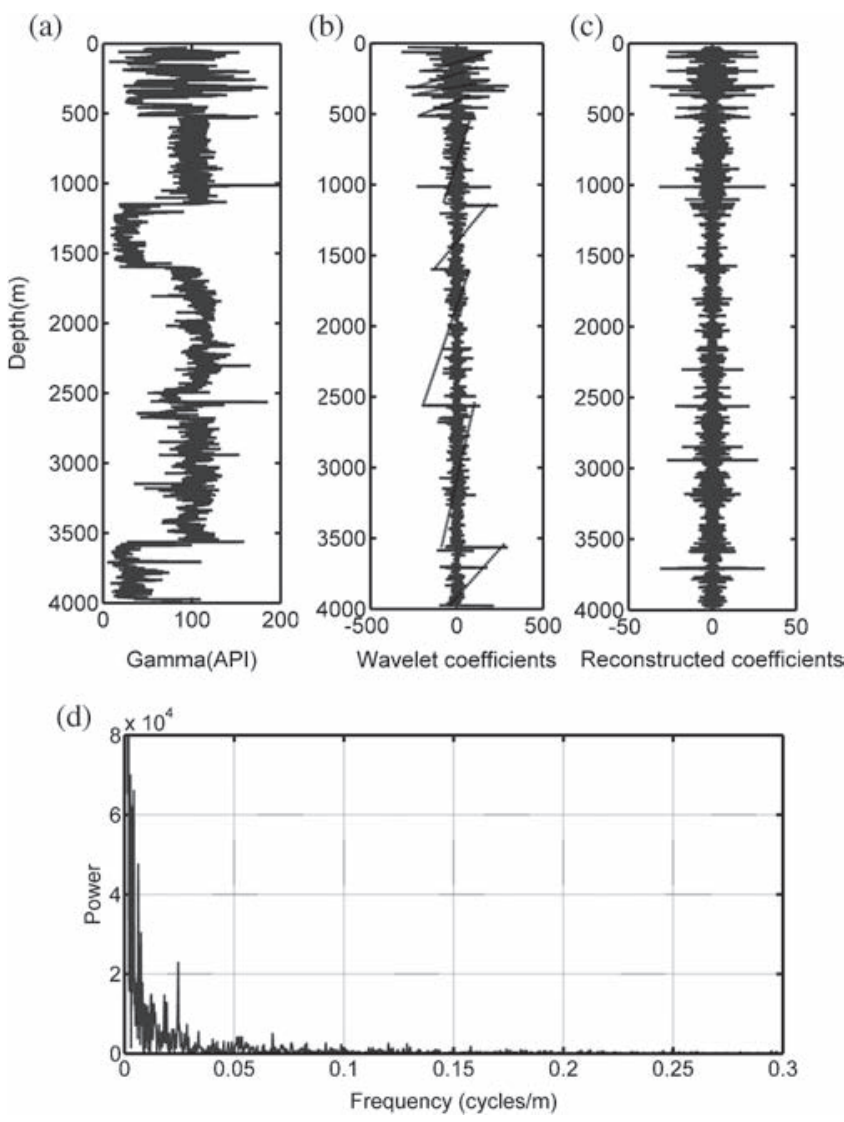

Figure 4. (a) KTB pilot hole gamma-ray log response. (b) Detail wavelet coefficient by using DWT of the signal. (c) Reconstruction of the signal from detail coefficient. (d) Power spectrum of the raw gamma-ray log. that case one needs to adopt different criteria to remove noise (e.g., amplitude thresholding). In DWT, the detail represents the high frequency signal (figure 3c). The detail coefficients obtained from the synthetic dataset produce spike of boundary against a particular depth, which is reflected by positive and negative coefficient values (figure 3c).

\subsection{Application to geophysical log dataset}

As mentioned previously, we used different logs (gamma-ray log, density log, resistivity log, porosity $\log$ and sonic $\log$ ) from both pilot and main borehole at KTB, Germany. First in order to examine the efficiency of the methodology, we tested in detail on gamma-ray log signal of the pilot borehole (figure 4a) and then applied on the entire dataset (both main hole and pilot hole). For the gamma ray $\log$, the decomposition was done up to third level to resolve the desired frequency content in the original log. Figure 4(b) exhibits the distribution of detail coefficients which were obtained using DWT. The distribution of reconstructed coefficient, which is well matched with the distribution of wavelet coefficients, shows additional details in the lithologic layer (figure 4c).

Power spectrum analysis of raw gamma rays suggest that well log records are assorted with certain amount of noise, especially at frequency greater than 0.05 (cycles $/ \mathrm{m}$ ), where some amount of ripples occurred (figure $4 \mathrm{~d}$ ). Therefore, we carried out (a)

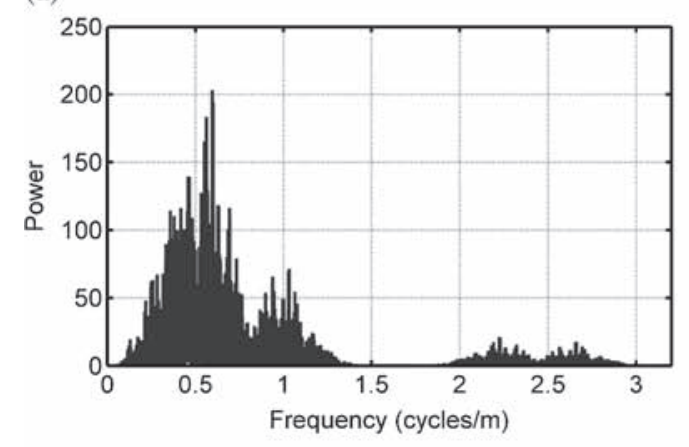

(b)

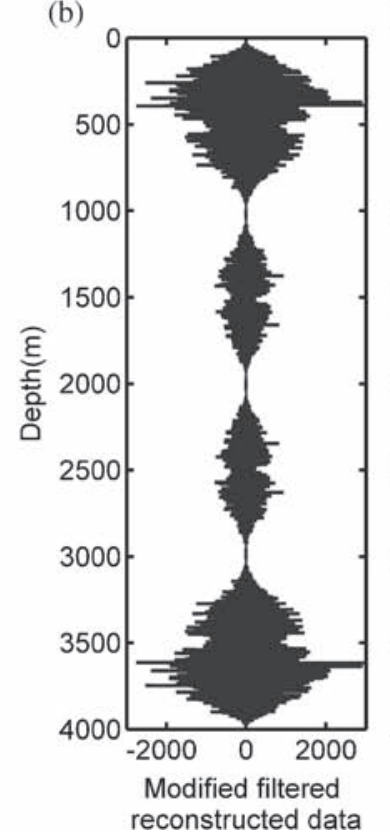

(c)

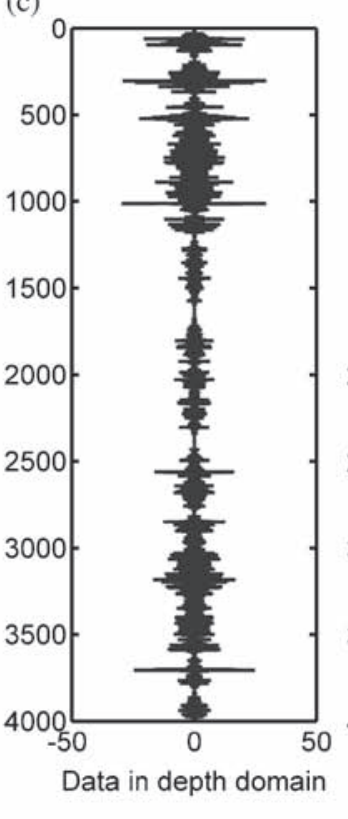

(d)

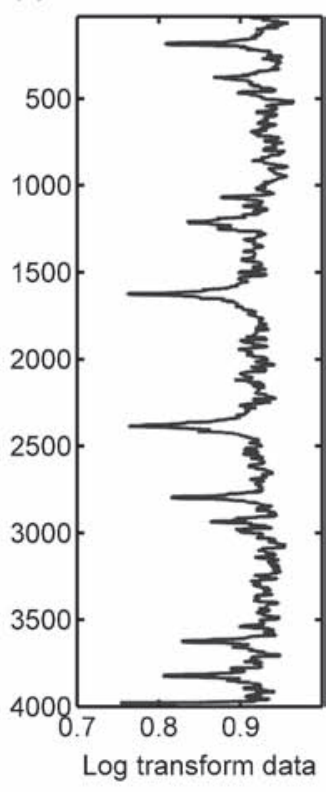

Figure 5. (a) Choice of frequency band from power spectrum estimate of the reconstructed gamma-ray log signal. (b) Modified detail component gamma-ray log signal after filtering. (c) Modified reconstructed gamma-ray log signal in depth domain. (d) Log transformed data of modified reconstructed gamma-ray log data. 
power spectrum analysis to choose the appropriate frequency band in order to eliminate noise component in the data (figure 5a). Here we are interested in high frequency component to gain more information with abrupt variation. Power spectrum is calculated from $\left(R_{D}\right)$ via FFT for each log data and appropriate frequency band is chosen for proper filtering. For gamma-ray log, there are two distinct frequency bands, $0-1.5$ cycles $/ \mathrm{m}$ and 1.9 3.0 cycles $/ \mathrm{m}$ in the spectrum (figure $5 \mathrm{a}$ ) and the strongest (or the most apparent) frequency band is $0.50-0.65$ cycles $/ \mathrm{m}$ (figure 5a). Therefore we have chosen the frequency, range $0.50-0.65$ cycles $/ \mathrm{m}$ (figure 5a) for filtering. After filtering with this frequency band, inverse FFT is applied on modified filtered reconstructed gamma-ray log data to transform the frequency domain to depth domain $\left(M_{R D}^{f}\right)$, (figure $5 \mathrm{~b}-\mathrm{c}$ ). Then logarithmic distribution of data against depth was calculated using equation (10) and is shown in figure 5(d). One can see that the logarithmic distribution/log transformed data of gamma ray log uncovers the additional details of lithologic changes/boundary compared to the original gamma ray signal (figures $5 \mathrm{~d}$ and $4 a)$.

We performed similar analysis for other logs. The distribution of detail wavelet coefficient indicates the presence of distinct layers for porosity log (figure 6a), density log (figure 6b), resistivity log (figure 6c) and sonic log (figure 6d). In DWT (a)
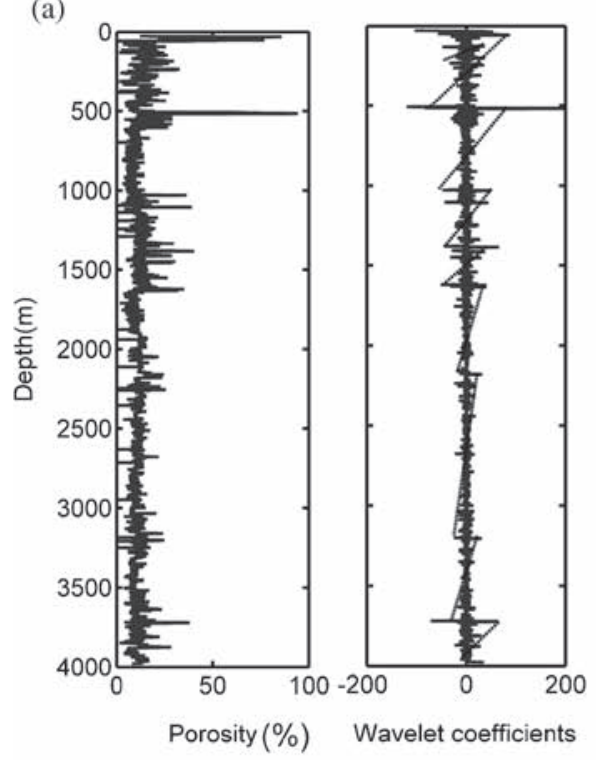

Wavelet coefficients
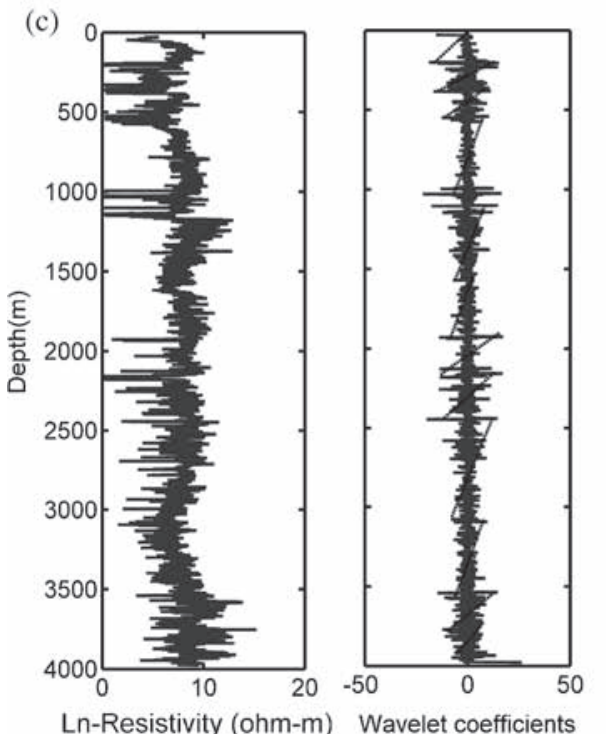
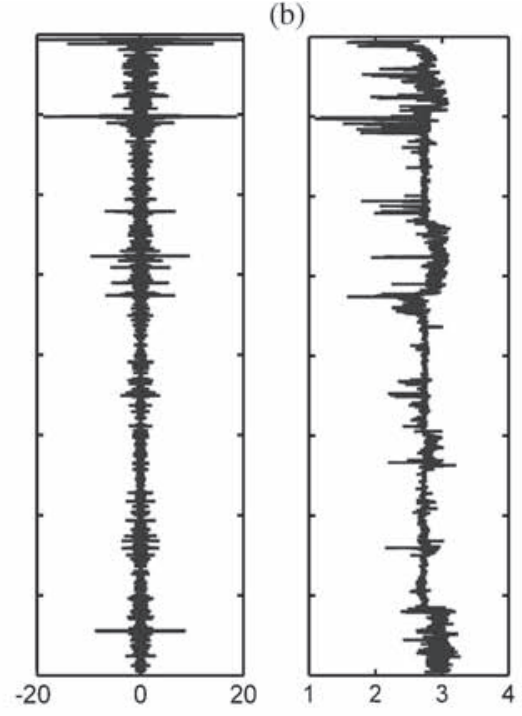

Density $(\mathrm{gm} / \mathrm{cc})$
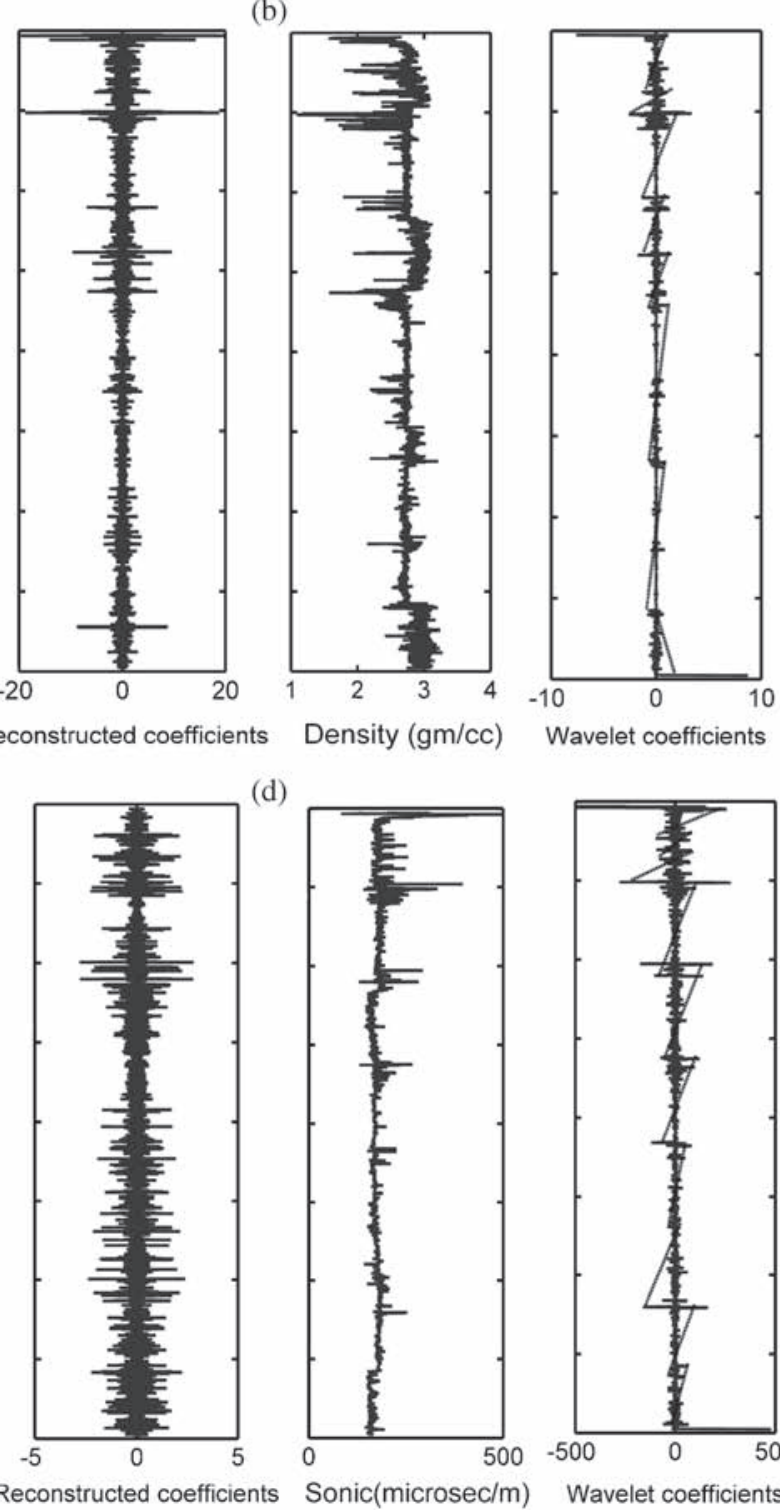

(d)

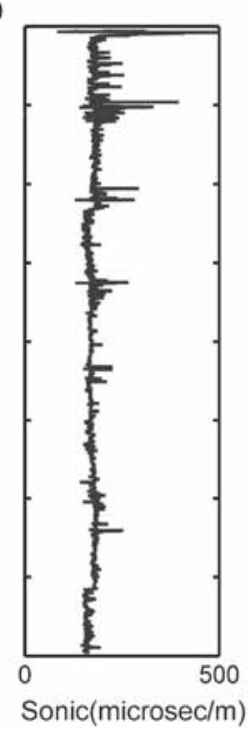

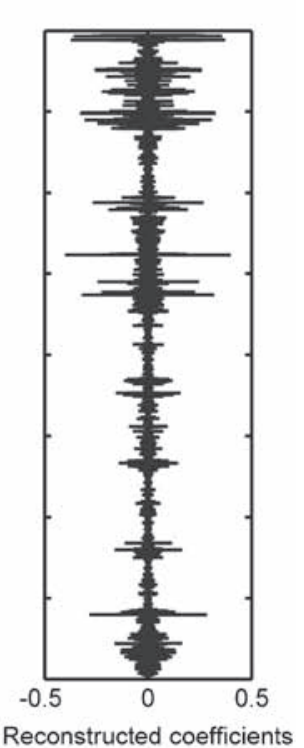
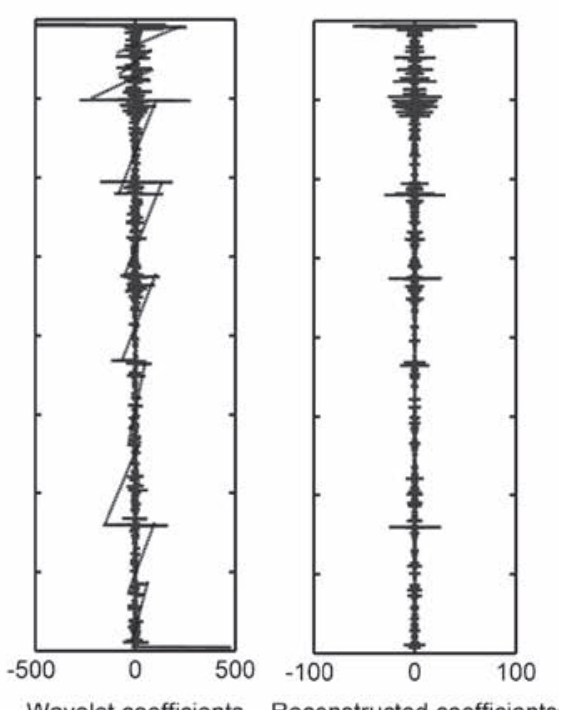

Figure 6. (a) KTB pilot hole porosity log response, detail wavelet coefficient of the log data and its reconstructed signal from detail coefficients. (b) KTB pilot hole density log response, detail wavelet coefficient of the log data and its reconstructed signal from detail coefficients. (c) KTB pilot hole resistivity log response, detail wavelet coefficient of the log data and its reconstructed signal from detail coefficients. (d) KTB pilot hole sonic log response, detail wavelet coefficient of the log data and its reconstructed signal from detail coefficients. 
coefficients distribution, horizontal lines indicate the presence of formation boundary bracketed by diagonal lines (figure 6 ). We performed power spectrum analysis of reconstructed data $\left(R_{D}\right)$ from the high frequency component for other logs for chosing the proper frequency band (figure 7). Accordingly, we have obtained appropriate frequency band for porosity log data $0.35-0.48$ cycles $/ \mathrm{m}$; for density $\log , 0.30-0.50$ cycles $/ \mathrm{m}$; resistivity $\log , 0.50-$ 0.66 cycles $/ \mathrm{m}$; and for sonic log, $0.53-0.73$ cycles $/ \mathrm{m}$ from power spectrum analysis (figure $7 \mathrm{a}-\mathrm{d}$ ). It may be noted that if the frequency band is chosen different from the reconstructed signal, the result of the log transformed data would change and the present boundary picking algorithm would not be able to resolve the lithological boundary. Therefore, frequency band is chosen such that it produces stable and satisfactory results.

We have done the filtering for other log signal and reconstructed it into depth domain to calculate the $\log$ transform of each $\log$ signal and compared with the original log signal. Then we have applied the boundary picking algorithm to the normalised log transformed data of well log data. Therefore, using the skilled algorithm of boundary picking to detect the bed boundary from normalised $\log$ transformed data is straightforward. There is no rule of thumb to select the weighting factor of individual log transformed data. One can assign a range of weight values (0.01-0.99) on a trial-and-error basis to produce stable and satisfactory results. In the present analysis, we have found the weighing factor 0.20 for density log transformed data, 0.16 for resistivity log transformed data, 0.31 for gamma log transformed data, 0.15 for porosity $\log$ transformed data and 0.18 for sonic log transformed data to produce stable result (figure 8). The wavelet transform-based boundary picking results for KTB pilot hole and KTB main hole are displayed on log transformed data (figures 8 and 10). To examine the authenticity of the results the picked boundary are plotted on the original log data of KTB pilot hole for depth ranging 28.0-4000 $\mathrm{m}$ and $\log$ data of KTB main hole for depth ranging 4000-7000 m (figures 9 and 11). It is seen that the results obtained with the wavelet transform-based method is closely matched with the lithologic layer changes in the KTB pilot and main hole. Moreover, we have compared the boundary picking results available/published over KTB pilot and main hole site (Emmermann and Lauterjung 1997; Pechnig et al. 1997; Leonardi and Kumpel 1999; Maiti and Tiwari 2005, 2010; Maiti et al. 2007). For comparison with pilot hole published results over KTB drill site, one can visually recognise presence of lithologic boundary at depths of $1156.259,1614.678$, and $3613.861 \mathrm{~m}$ which are very close to boundaries reported in earlier studies (a)

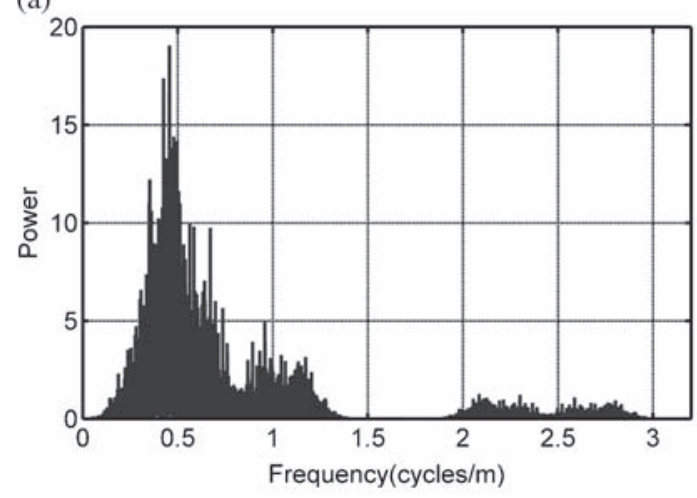

(c)

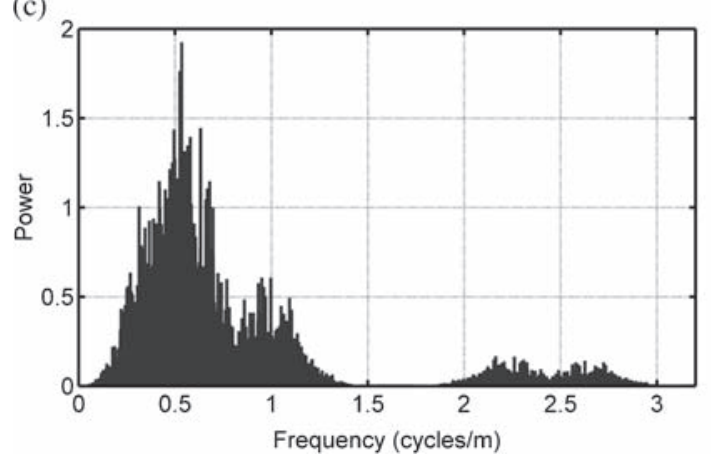

(b)

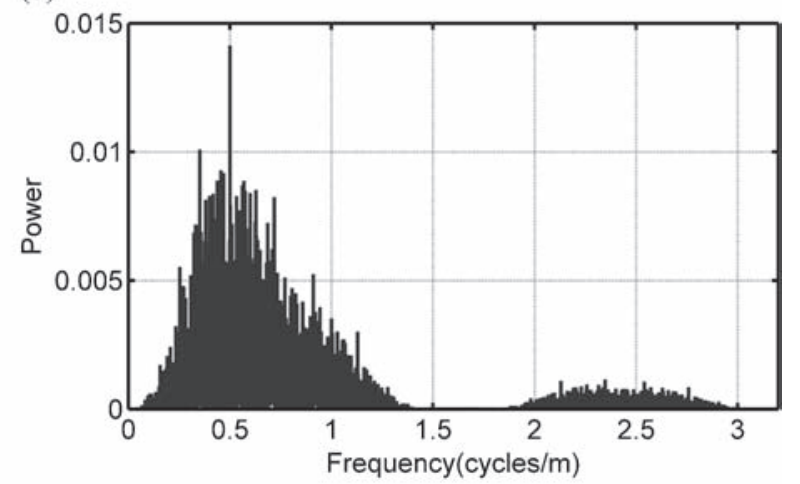

(d)

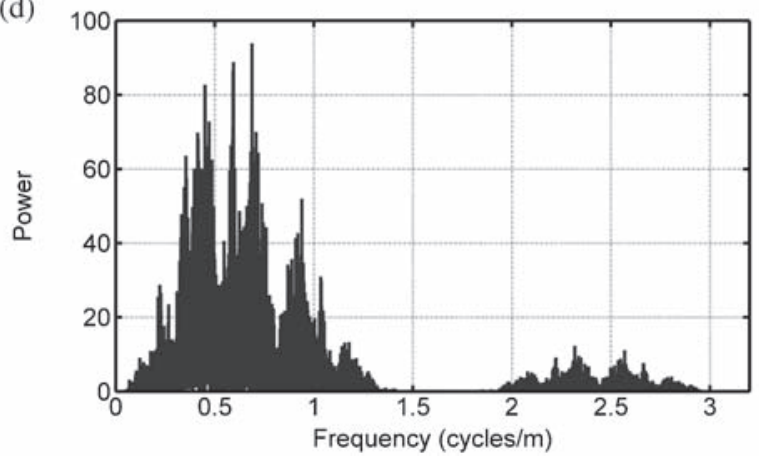

Figure 7. Power spectrum analysis of reconstructed data $\left(R_{D}\right)$ from the high frequency component for (a) porosity log, (b) density log, (c) resistivity log, and (d) sonic log. 

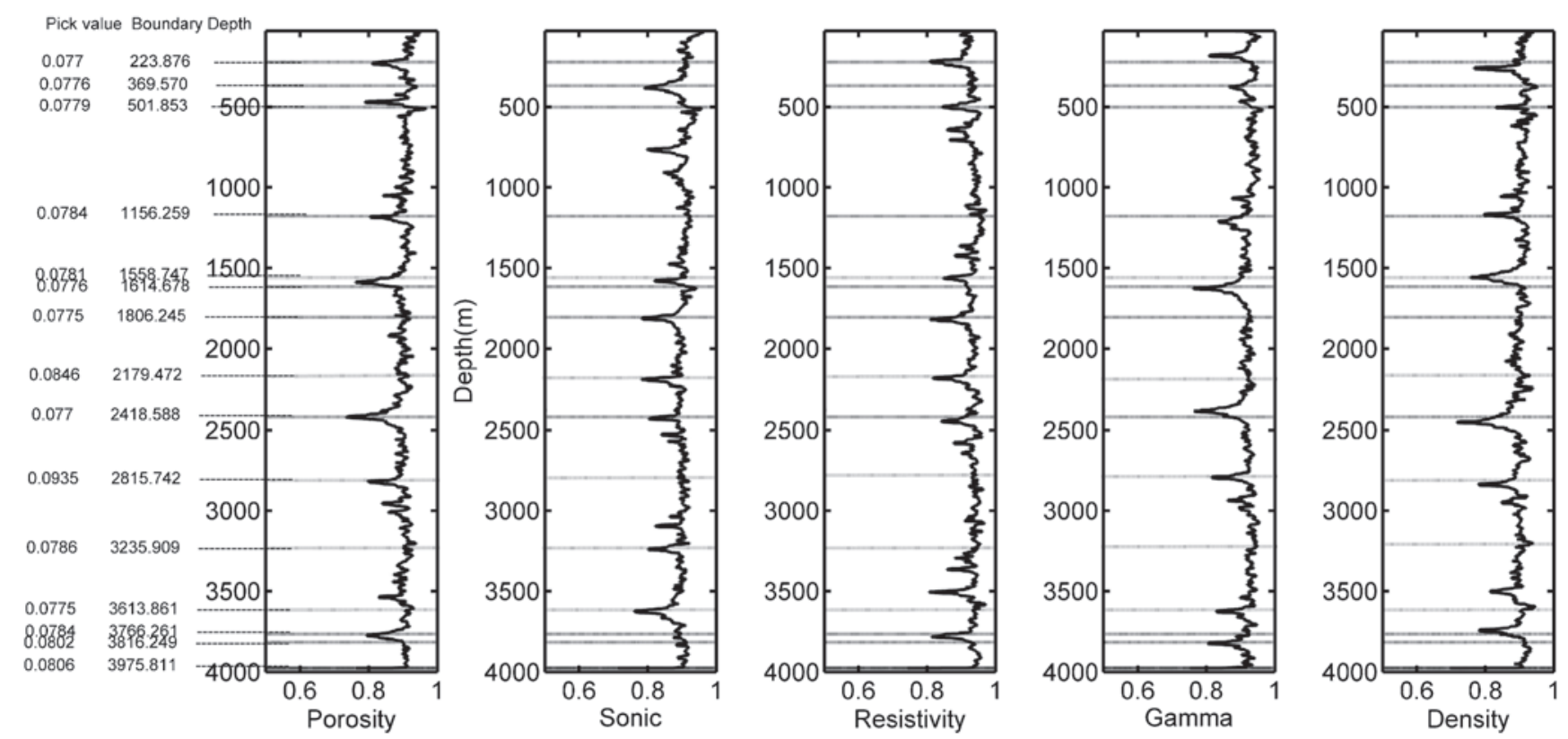

Figure 8. Lithological boundaries of pilot borehole are plotted over log transformed data.
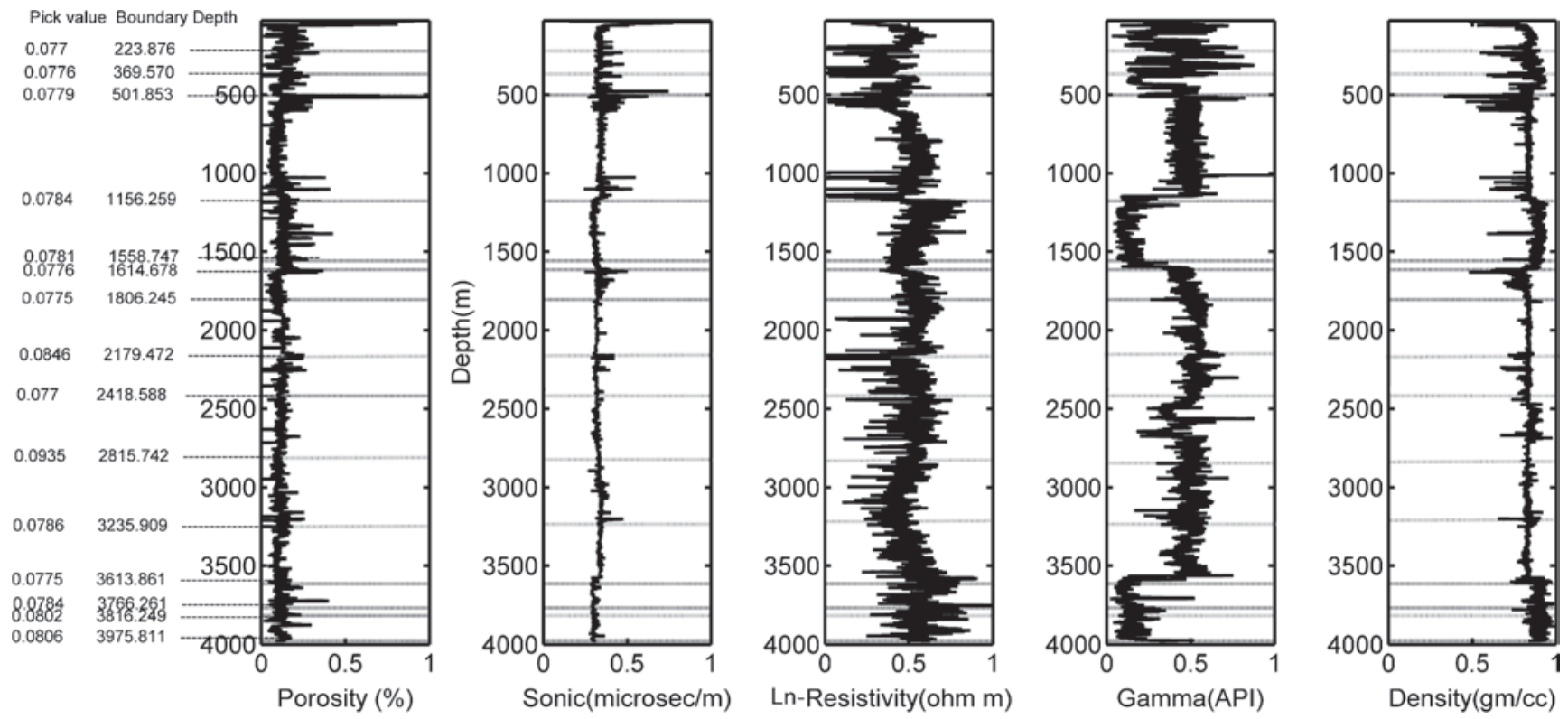

Figure 9. Lithological boundaries of pilot borehole are plotted over original log data.

(Emmermann and Lauterjung 1997; Pechnig et al. 1997; Leonardi and Kumpel 1999). A close examination of the results suggests that excepting at depths 5184.95, 5539.13, 6436.46 and $6573.01 \mathrm{~m}$, the present wavelet based method fairly agrees well with the published results over KTB main hole site especially at the depth of 4404.665, 4658.258, 5262.953, 5341.010, 5419.039, 5656.174, 5773.217, 5948.782, 6007.303 and $6377.944 \mathrm{~m}$ (Pechnig et al. 1997; Leonardi and Kumpel 1999; Maiti and Tiwari 2005, 2010; Bosch et al. 2013). In addition to this, present wavelet-based method provides additional details which match nicely with the pattern of original well log signal at the depth of 4217.518 , 4593.641, 5204.612, 5837.987, 6566.307, 6709.105, and $6834.683 \mathrm{~m}$ (figures 10-11). Moreover, waveletbased present method which detected boundaries at depths of 4217.518, 4593.641, 5204.612 and $5837.987 \mathrm{~m}$ at main hole is also well matched with the fuzzy logic-based results by Bosch et al. (2013). To examine further the linking of lithological boundaries with formation properties, we manually checked the physical properties at those new boundaries and summarised results in tabular form (table 1). The deciding factors (particularly physical property/combination of physical properties) to 

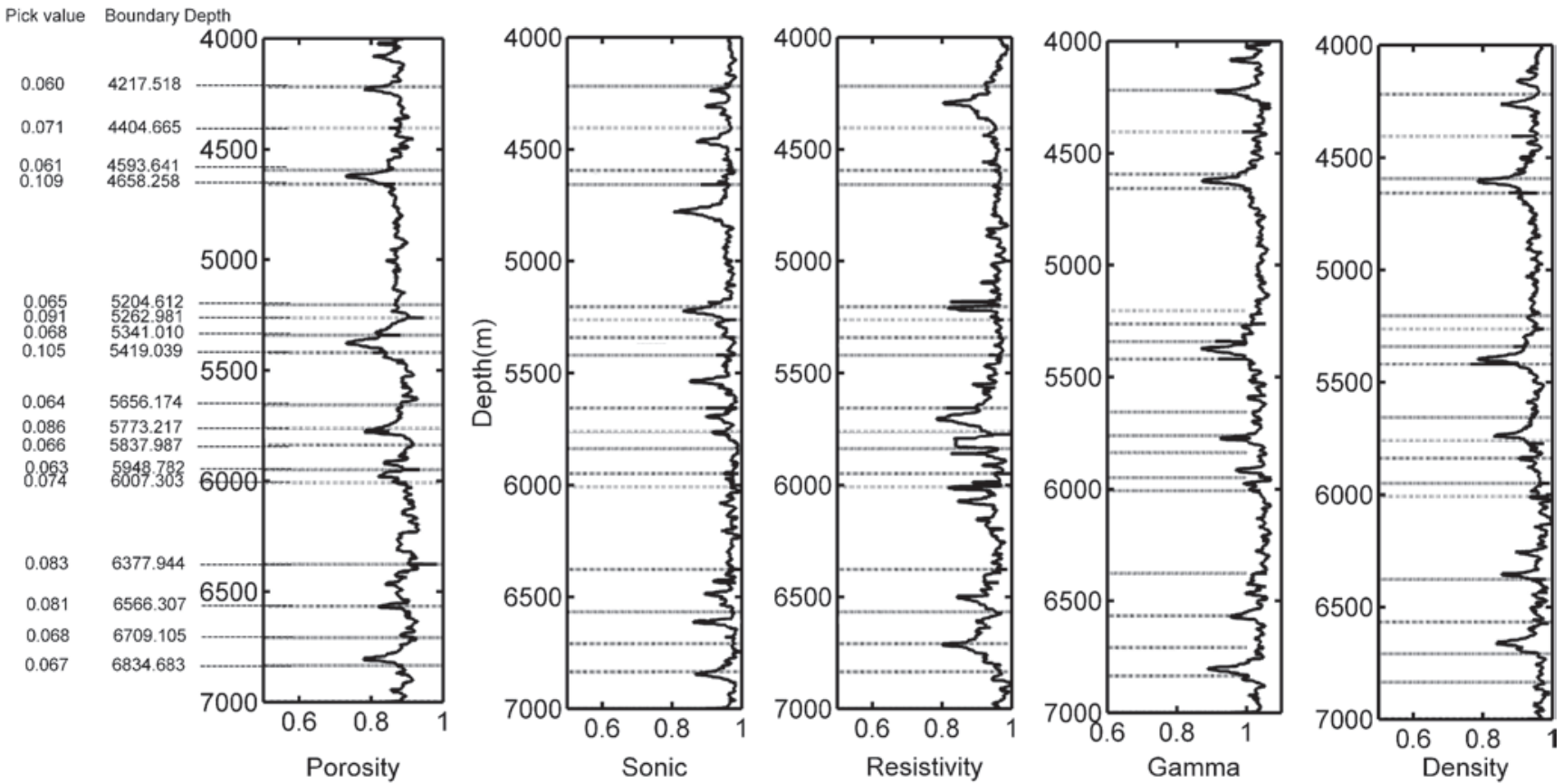

Figure 10. Lithological boundaries of main borehole are plotted over log transformed data.
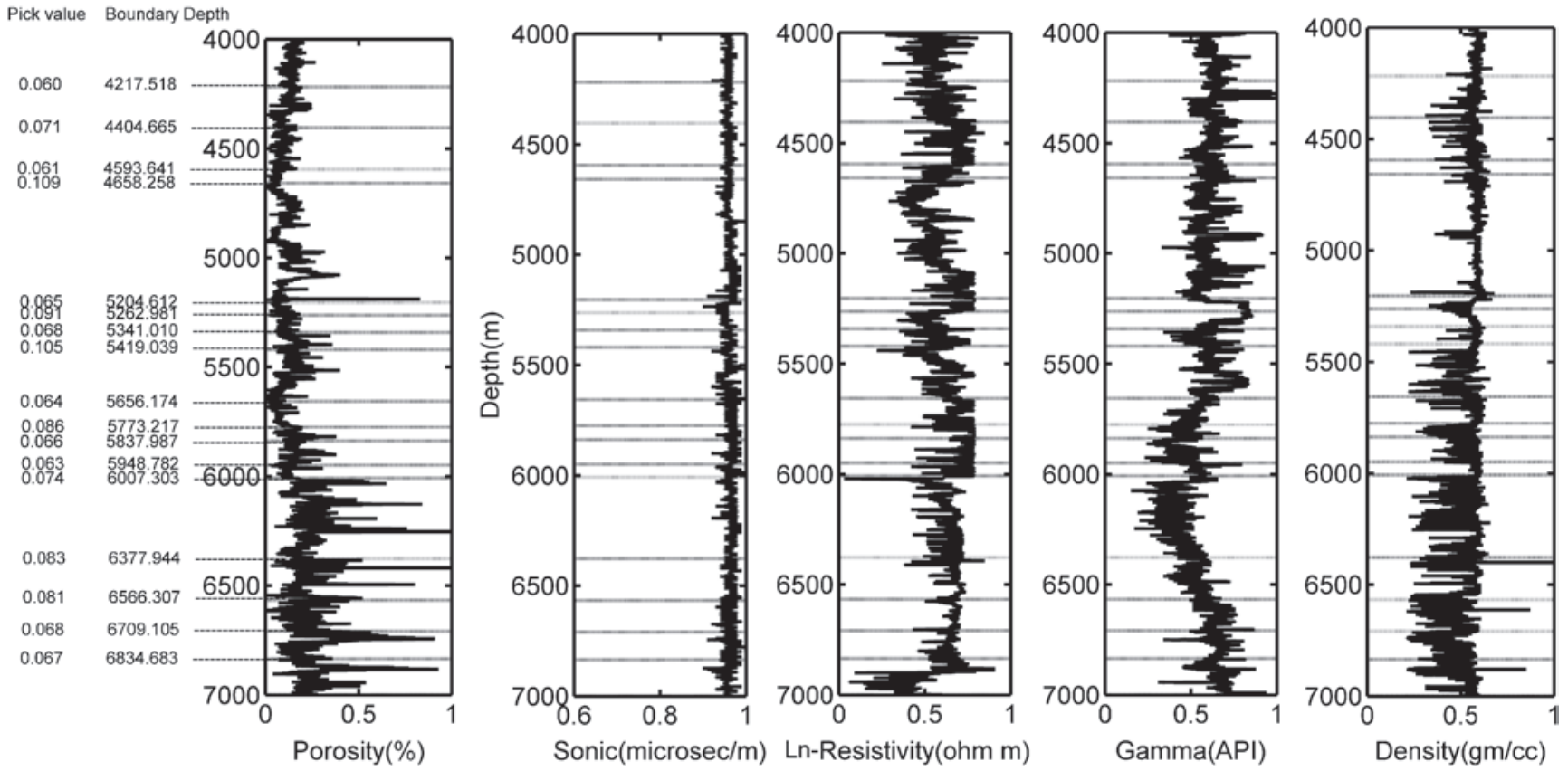

Figure 11. Lithological boundaries of main borehole are plotted over original log data.

detect the new boundary are given in table 1 . It is encouraging to find that formation boundaries detected by the present method is in tune with the formation property changes (table 1). When a boundary is identified, physical properties change across the boundary and therefore, average properties of the formations above and below are also changed (table 1). It may be noted that in the boundary picking algorithm as described, we considered the boundary depth at the beginning of the step and the changes of the physical properties are highlighted at that depth for all new boundaries. For example, at a depth of $4217.518 \mathrm{~m}$, density changes from 2.717 to $2.893 \mathrm{gm} / \mathrm{cc}$, porosity changes from $11.358 \%$ to $13.696 \%$, gamma ray intensity changes from 80.777 to $76.848 \mathrm{API}$, sonic changes from 196.735 to $195.873 \mathrm{micro} \mathrm{sec} / \mathrm{m}$ and logarithmic value of resistivity changes form 6.832 to $6.636 \mathrm{Ohm}-\mathrm{m}$. These changes of $\mathrm{log}$ values (porosity, density and gamma ray intensity) 


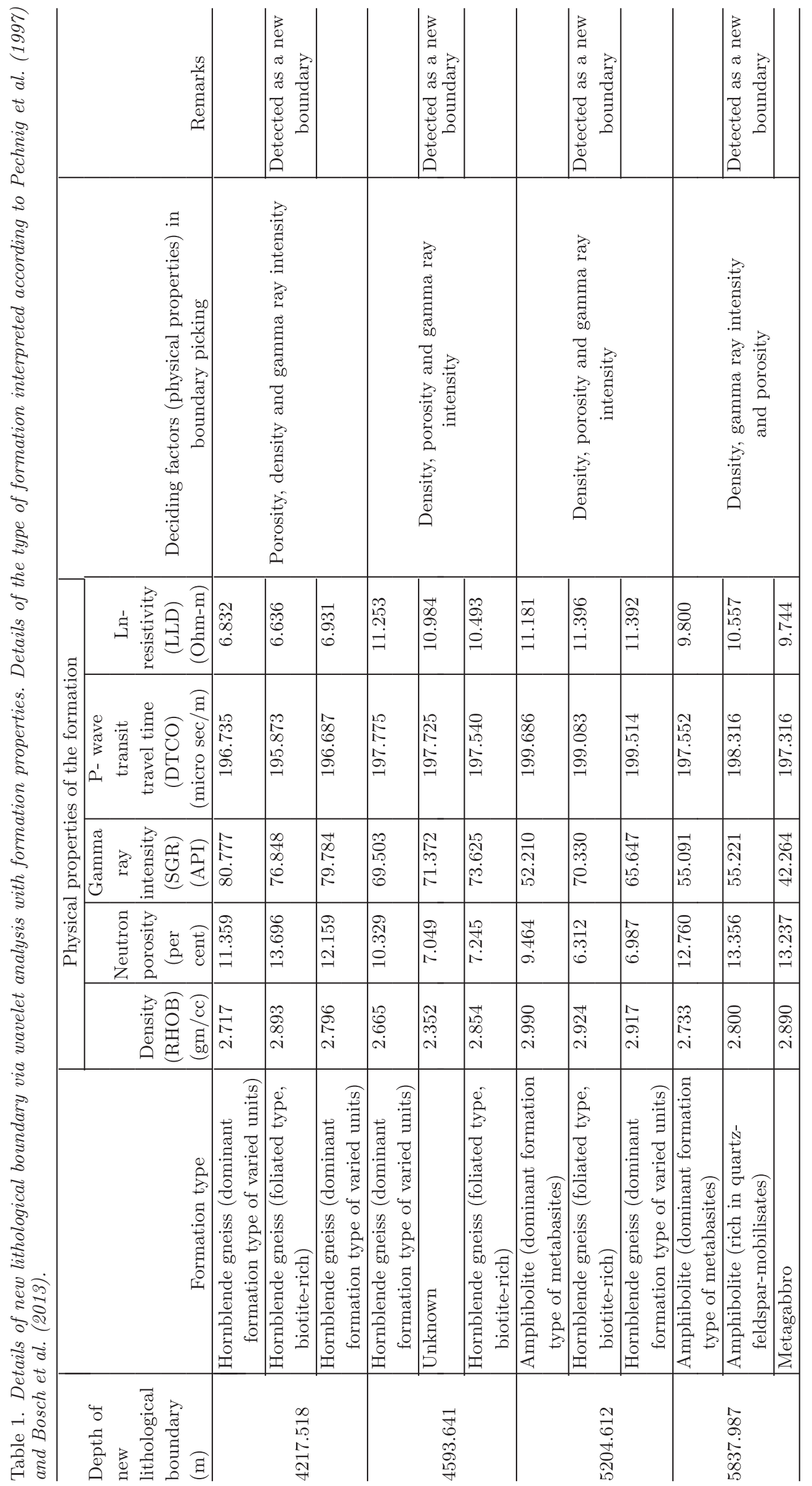




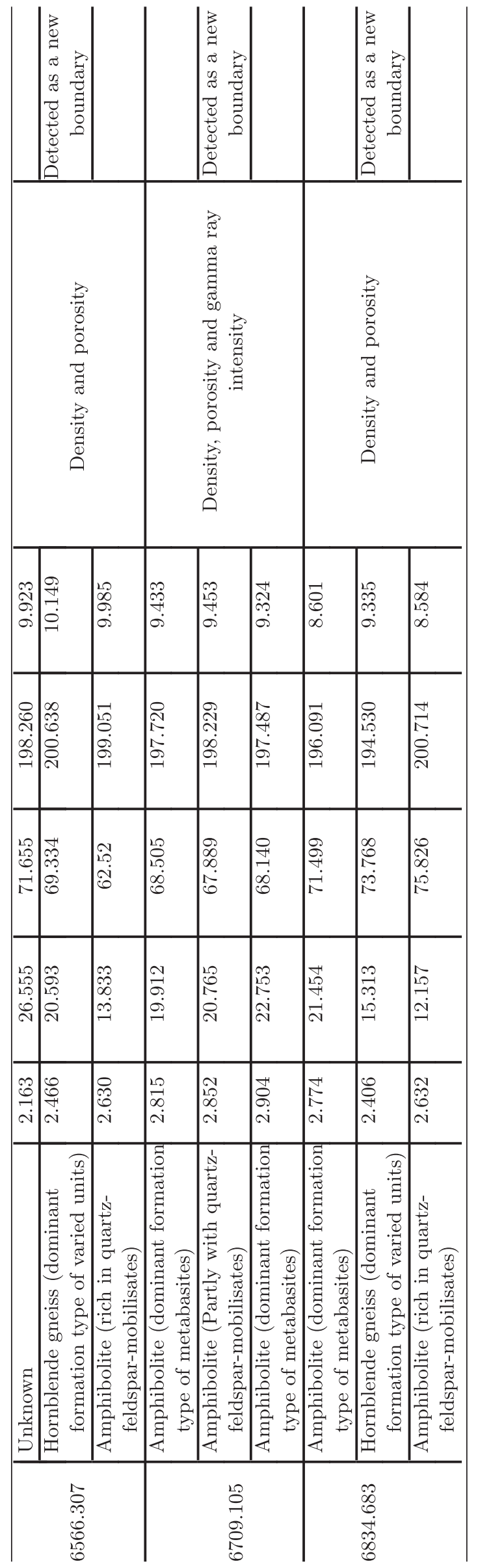

may possibly be due to the presence of high mafic and dense mineral-like biotite in the biotiterich-hornblende gneiss than the hornblende gneiss (table 1). Similarly, at the depth of $4593.641 \mathrm{~m}$, density changes from 2.665 to $2.352 \mathrm{gm} / \mathrm{cc}$, porosity changes from $10.329 \%$ to $7.049 \%$, gamma ray intensity changes from 69.503 to $71.372 \mathrm{API}$, sonic changes from 197.775 to 197.725 micro sec/m and logarithmic value of resistivity changes form 11.253 to $10.984 \mathrm{Ohm}-\mathrm{m}$. Here again the above variations may be interpreted in terms of changes in (density, porosity and gamma ray intensity) formation from hornblende gneiss (dominant formation type of varied units) to 'unknown' type (table 1). Likewise, at the depth of $5204.612 \mathrm{~m}$, density changes from 2.990 to $2.924 \mathrm{gm} / \mathrm{cc}$, porosity changes from $9.464 \%$ to $6.312 \%$, gamma ray intensity changes from 52.210 to $70.330 \mathrm{API}$, sonic changes from 199.686 to $199.083 \mathrm{micro} \mathrm{sec} / \mathrm{m}$ and logarithmic value of resistivity changes form 11.181 to $11.396 \mathrm{Ohm}-\mathrm{m}$. Distinct changes of log values (density, porosity and gamma ray intensity) observed at the above depth range may likely due to change of formation from amphibolite to hornblende gneiss (foliated type, biotite rich) (table 1). At this boundary, one can see that mainly gamma ray intensity values are increased. This may be related to the presence of more mafic mineral-like biotite in the hornblende gneiss than the amphibolite (table 1). Similarly, at the depth of $5837.987 \mathrm{~m}$, density changes from 2.733 to $2.800 \mathrm{gm} / \mathrm{cc}$, porosity changes from $12.760 \%$ to $13.356 \%$, gamma ray intensity changes from 55.091 to $55.221 \mathrm{API}$, sonic changes from 197.552 to 198.316 micro sec/m and logarithmic value of resistivity changes form 9.800 to $10.557 \mathrm{Ohm}-\mathrm{m}$. The changes observed in the log values of density, gamma ray intensity and porosity at $5837.987 \mathrm{~m}$ depth probably indicate the presence of more quartz-feldspar mobilisates content in the quartz-feldspar mobilisates-rich-amphibolite than the amphibolite (table 1). Likewise, at the depth of $6566.307 \mathrm{~m}$, density changes from 2.163 to $2.466 \mathrm{gm} / \mathrm{cc}$, porosity changes from $26.555 \%$ to $20.593 \%$, gamma ray intensity changes from 71.655 to 69.334 API, sonic changes from 198.260 to $200.638 \mathrm{micro} \mathrm{sec} / \mathrm{m}$ and logarithmic value of resistivity changes form 9.923 to 10.149 Ohm-m. Variations in the log values (density, and porosity) noticed near $6566.307 \mathrm{~m}$ depth suggest the change of formation from 'unknown' type to hornblende gneiss (dominant formation type of varied units) (table 1). Again at the depth of $6709.105 \mathrm{~m}$, density changes from 2.815 to $2.852 \mathrm{gm} / \mathrm{cc}$, porosity changes from 19.912 to $20.765 \%$, gamma ray intensity changes from 68.505 to 67.889 API, sonic changes from 197.720 to $198.229 \mathrm{micro} \mathrm{sec} / \mathrm{m}$ and logarithmic value of resistivity changes form 9.433 to $9.453 \mathrm{Ohm}-\mathrm{m}$. The observed variation in the log 
values (density, porosity and gamma ray intensity) is due to the presence of more quartz-feldspar mobilisates content in the quartz-feldspar mobilisatesrich-amphibolite than the amphibolite at this depth (table 1). Similarly, at the depth of 6834.683 $\mathrm{m}$, density changes from 2.774 to $2.406 \mathrm{gm} / \mathrm{cc}$, porosity changes from $21.454 \%$ to $15.313 \%$, gamma ray intensity changes from 71.499 to 73.768 API, sonic changes from 196.091 to $194.530 \mathrm{micro} \mathrm{sec} / \mathrm{m}$ and logarithmic value of resistivity changes form 8.601 to $9.335 \mathrm{Ohm}-\mathrm{m}$. Change of formation from amphibolite to hornblende gneiss (dominant formation type of varied units) may be the likely cause for the observed changes in the log values of density and porosity (table 1). Further, it may be noted that at this boundary, observed changes of density and porosity values could be related to the possible presence of more plagioclase in the hornblende gneiss than the amphibolite (table 1).

\section{Discussions}

In the complex geological situations, such as one KTB borehole, it is somewhat difficult to interpret the nonlinear and nonstationary nature of geological records against depth. This is due to the fact that the information pertaining to the exact lithological succession is sometimes obscured by the episodes of complex metamorphism. One of the better options left with us was to develop an efficient technique for the interpretation of such complex well log signals. The application of WT was explored and experimented on synthetic signal assorted with additive Gaussian noise/AR(1) model in tune with the more likely geological situation, presuming that certain amount of noise would make the signal nonstationary. It may be mentioned that the CWT-based scalogram analyses are commonly used to image different types of lithology through visualising changes in the signals (high and low wavelet co-efficient) characteristics. Often these plots show rather striking features that our eyes are drawn toward, but that can be largely attributed to the fact that CWT coefficients are typically highly correlated both spatially and temporarily (Percival 2008). Appropriate statistical assessment of significance of these features involves some subtle issues (Maraun et al. 2007), particularly, if they are picked out by eye prior to being assessed. Moreover, the fact that collections of coefficients from DWTs are approximately, uncorrelated, makes it easier to implement our algorithm. The choice of an appropriate mother wavelet is the foremost task for research related to wavelet analysis (Sang et al. 2013). It may be noted that, at present, there is no existing criterion that determines the correct mother wavelet for a specific application (Liu et al. 2014). Further the selection of any wavelet, as an ideal one should be based on the matching characteristic of the signal/data under study. Here in order to decode/detect discontinuities from well log data, the Haar wavelet, resembling step function, with DWT algorithm is found adequate to image most of the discontinuities over the KTB site. The DWT-based analysis demonstrates the presence of known discontinuities as well as some other boundaries, which were not recognizable by visual interpretation. Further, the very meaning of 'boundary' implies that it separates/distinguishes the subsurface formations having different physical properties. Accordingly, the well log data would show different characteristics associated with these formations above and below the boundary. To examine the authenticity of the new boundaries we manually checked the values of the formation properties above and below the boundary depth (table 1). It may be noted that the new boundaries are well described by the changes of formation properties. It is worthwhile to note that if the choice of the frequency band is not correct then logarithmic distribution of the modified reconstructed signal would show different results from original signal and in that case, it is not possible to obtain proper boundary picking value. This is because of the fact that the sum of the picking value depends on the frequency band of the reconstructed signal. In order to achieve the stability, we have chosen different frequency bands by trial-and-error method for each log data and compared the all log transform signal with the original (figures 9-11). The results using the present DWTbased method over KTB bore hole is of considerable significance for imaging the discontinuities of inhomogeneous earth crust over KTB, Germany. Further, this result could be useful to gain better insights into the geodynamic system of the study area.

\section{Conclusions}

The lithological boundary detection algorithm based on the wavelet transform combined with Fourier transform technique is developed and successfully applied on the KTB pilot and main borehole data. Our main findings can be summarized as follows:

- The method based on wavelet transform is potential to detect boundaries from the nonstationary geophysical well log signal.

- The application of the new method to KTB pilot and main hole shows that the method is successful to discern known lithologic boundaries, as well as some finer details, which was missed in previous investigations over KTB, Germany. 
Changes in physical properties of the formation confirm the presence of these new boundaries.

- The method could be useful to analyse data taken over other complex geological provinces around the world.

\section{Acknowledgements}

We are thankful to Prof. D C Panigrahi, Director, Indian School of Mines, Dhanbad, for giving permission to publish this work and also thankful to Head of the Department, Applied Geophysics. One of the authors, Amrita Singh, is grateful to Indian School of Mines, Dhanbad for providing junior research fellowship to carry out the research work. We are also thankful to Prof. Hans-Joachim Kumpel for providing the KTB data. We sincerely thank the anonymous reviewers who have helped us to improve the manuscript in many interesting ways. Partial financial benefit from the Ministry of Earth Sciences, Govt. of India, New Delhi, India, is also thankfully acknowledged (Grant No: MoES/P.O. (Geosci)/44/2015).

\section{References}

Adamowski J and Chan H F 2011 A Wavelet neural network conjunction model for groundwater level forecasting; J. Hydrol. 407 28-40.

Alvarez G, Sanso B, Michelena R J and Jimenez J R 2003 Lithologic charecterizations of a reservoir using continuous wavelet transform; IEEE Trans. Geosci. Remote Sens. 41(1) 59-65, doi: 10.1109/TGRS.2002.808065.

Boggess A and Narcowich F J 2001 A First Course in Wavelets with Fourier Analysis; Prentice-Hall, Englewood Cliffs, NJ, 283p.

Bosch D, Ledo J and Queralt P 2013 Fuzzy logic determination of lithologies from well log data: Application to the KTB project data set; Surv. Geophys. 34 413-439, doi: 10.1007/s10712-013-9242-2.

Chandrashekhar E and Rao V E 2012 Wavelet analysis of geophysical well-log data of Bombay offshore basin, India; Math. Geosci. 44 901-928.

Chamoli A, Bansal A R and Dimri V P 2007 Wavelet and range approach for the Hurst coefficient for short and long time series; Comput. Geosci. 33 83-93.

Chamoli A, Swaroopa Rani, Srivastava K, Srinagesh D and Dimri V P 2010 Wavelet analysis of the seismograms for tsunami warning; Nonlin. Process. Geophys. 17 569-574.

Daubechies I 1992 Ten Lectures on Wavelets; Soc. for Ind. Appl. Math., Philadelphia, Pa, 357p.

Dewan J T 1983 Essentials of Modern Open-Hole Log Interpretation; PennWell Publishing Company, Tulsa, US, $361 \mathrm{p}$.

Doveton JH 1986 Log Analysis of Subsurface Geology Concepts and Computer Methods; Wiley, New York, NY, $273 p$.

Emmermann R and Lauterjung J 1997 The German continental deep drilling program KTB: Overview and major results; J. Geophys. Res. 102 18,179-18,201.

Frantziskonis G and Denis A 2003 Complementary entropy and wavelet analysis of drilling-ability data; Math. Geol. 35(1) 89-103.
Goumas S K, Zervakis M E and Stavrakakis G S 2002 Classification of washing machines vibration signals using discrete wavelet analysis for feature extraction; IEEE Trans. Instr. Meas. 51(3) 497-508.

Goupillaud R A, Grossmann A and Morlet J 1985 Cycleoctave and related transform in seismic signal analysis; Geoexploration 23 85-102.

Hsieh B Z, Lewis C and Lin Z S 2005 Lithology identification of aquifers from geophysical well logs and fuzzy logic analysis: Shui-Lin Area, Taiwan; Comput. Geosci. $31263-275$.

Jang J S R and Jang Y S 2003 Microcontroller implementation of melody recognition: A prototype; Proceedings of the 11th ACM International Conference on Multimedia, Berkeley, CA, USA, pp. 452-453.

Javid M and Tokhmechi B 2012 Formation interface detection using gamma ray log: A novel approach; $J$. Mining \& Environment 3(1) 41-50.

Kumar P and Foufoula-Georgiou E 1997 Wavelet analysis for geophysical applications; Rev. Geophys. 35(4) 385412, doi: 10.1029/97RG00427.

Lanning E N and Johnson D M 1983 Automated identification of rock boundaries: An application of the Walsh transform to geophysical well-log analysis; Geophysics 48 197-205.

Lau K M and Weng H 1995 Climate signal detection using wavelet transform: How to make a time series sing; Bull. Am. Meteor. Soc. 76 2391-2402.

Leonardi S and Kumpel H 1999 Fractal variability in super deep borehole implications for the signature of crustal heterogeneities; Tectonophys. 301 173-181.

Leung A K, Chau F and Gao J 1998 A review on application of wavelet transform techniques in chemical analysis; Chemometrics and Intelligent Laboratory Systems $\mathbf{4 3}$ 165-184.

Liu Z, Zhou P, Chen G and Guo L 2014 Evaluating a coupled discrete wavelet transform and support vector regression for daily and monthly stream flow forecasting; J. Hydrol. $5192822-2831$.

Maiti S and Tiwari R K 2005 Automatic detection of lithologic boundaries using the Walsh transform: A case study from the KTB borehole; Comput. Geosci. 31(8) 949-955.

Maiti S and Tiwari R K 2010 Neural network modelling and an uncertainty analysis in Bayesian framework: A case study from the KTB borehole site; J. Geophys. Res. 115 B10208, doi: 10.1029/2010JB000864.

Maiti S, Tiwari R K and Hans-Joachim Kuempel 2007 Neural network modeling and classification of litho-facies using well log data: A case study from KTB borehole site; Geophys. J. Int. 169 733-746. http://dx.doi.org/10. 1111/j.1365-246X.2007.03342.x.

Mallat S G 1989 A theory for multi-resolution signal decomposition: The wavelet representation; IEEE Trans. Pattern Analysis and Mach. Intelligence 11(7) 674-693, doi: 10.1109/34.192463.

Maraun D, Kurths J and Holschneider M 2007 Nonstationary Gaussian processes in wavelet domain: Synthesis, estimation, and significance testing; Phys. Rev. E 75 016707.

Misti M, Misti Y, Oppenheim G and Poggi J M 2007 Wavelet Toolbox 4 for Use with MATLAB User's Guide; The Math Works Inc., Natick, M.A., USA, pp. 1-1170.

Morlet J, Arens G, Fourgeau E and Giard D 1982 Wave propagation and sampling theory. Part I: Complex signal and scattering in multilayered media; Geophysics $\mathbf{4 7 ( 2 )}$ $203-221$.

Oppenheim A V, Schafer R W and Buck J R 1999 DiscreteTime Signal Processing; Prentice-Hall, Englewood Cliffs, NJ, 879p. 
Pan S, Hsieh B, Lu M and Lin Z 2008 Identification of stratigraphic formation interfaces using wavelet and Fourier transform; Comput. Geosci. 34 77-92.

Percival D B 2008 Analysis of geophysical time series using discrete wavelet transforms: An overview; In: Nonlinear Time Series Analysis in the Geosciences - Applications in Climatology, Geodynamics, and Solar-terrestrial Physics (eds) Donner R V and Barbosa S M, Springer, Berlin/Heidelberg.

Pechnig P, Haverkamp S, Wohlenberg J, Zimmermann G and Burkhardt H 1997 Integrated interpretation in the German Continental Deep Drilling Program: Lithology, porosity, and fracture zones; J. Geophys. Res. 102 18,363-18,390.

Perez-Munoz T, Velasco-Hernandez J and HernandezMartinez E 2013 Wavelet transform analysis for lithological characteristics identification in siliciclastic oil fields; $J$. Appl. Geophys. 98 298-308.

Sang Y F, Wang Z and Liu C 2013 Discrete wavelet-based trend identification in hydrologic time series; Hydrol. Process. 27 2021-2031.

Seo Y, Kim S, Kisi O and Singh V P 2015 Daily water level forecasting using wavelet decomposition and artificial intelligence techniques; J. Hydrol. 520 224243.

Soliman M Y, Ansah J, Stephenson S and Mandal B 2003 Application of wavelet transform to the analysis of pressure-transient data; SPE Reservoir Eval. Eng. 6(2) 89-99.

Wickerhauser M V 1994 Adapted Wavelet Analysis from Theory to Software; A K Peters, Wellesle, MA, USA, 486p.

MS received 16 January 2015; revised 6 February 2016; accepted 10 February 2016

Corresponding editor: PAWAN DEWANGAN 